Revista Destaques Acadêmicos, Lajeado, v. 12, n. 1, 2020. ISSN 2176-3070

DOI: http://dx.doi.org/10.22410/issn.2176-3070.v12i1a2020.2370

http://www.univates.br/revistas

\title{
A MIGRAÇÃO PARA O VALE DO TAQUARI/RS: UMA ANÁLISE DOS DETERMINANTES E EXPECTATIVAS DOS MIGRANTES
}

\author{
Andréia Braun Becker ${ }^{1}$, Fernanda Cristina Wiebusch Sindelar ${ }^{2}$
}

\begin{abstract}
Resumo: Os movimentos migratórios modificam o comportamento de uma localidade influenciando as dinâmicas demográficas e o desenvolvimento de regiões. No período recente, a região do Vale do Taquari/RS tem apresentado um crescimento demográfico superior à média estadual, revelando a existência de dinamismo econômico regional, assim como, uma capacidade de atração de migrantes provenientes de outras regiões. Neste sentido, o objetivo deste estudo foi compreender os motivos que instigaram as famílias a migrarem para o Vale do Taquari/RS nos últimos 10 anos. É relevante compreender os fatores intrínsecos desse processo, uma vez que o comportamento econômico e as políticas de desenvolvimento dos municípios são diretamente influenciados pelos fluxos migratórios. A pesquisa classificou-se como exploratória e descritiva, com abordagem qualitativa, através da realização de entrevistas com migrantes. Os resultados indicaram que os principais fatores que atraíram as famílias para a região estiveram associados ao seu desenvolvimento, o qual tem oportunizado melhores condições de emprego, qualidade de vida e acessibilidade a diversas localidades do estado. Além disso, constatou-se que as perspectivas das famílias em relação ao Vale do Taquari correlacionam-se tanto a ascensão, quanto profissional.
\end{abstract}

Palavras-chave: Migração. Fatores. Expectativas. Vale do Taquari.

\section{Introdução}

Desde os tempos antigos, a migração da população tem influenciado os processos de urbanização e redistribuição espacial da população, impactando tanto os locais de recebimento quanto os de perda migratória (BEANINGER, 2012). Por este motivo, é crucial compreender a migração e os seus elementos intrínsecos para entender o sistema de urbanização e os outros impactos que esta traz para as regiões (OLIVEIRA; PEREIRA; BLOIS, 2010).

1 Bacharel em Administração pela UNIVATES.

2 Doutora em Ambiente e Desenvolvimento pela UNIVATES. Professora da UNIVATES. 
Os movimentos populacionais estão ligados a diversos fatores, entre os quais estão a mobilidade, o crescimento das cidades, as desigualdades de renda e sociais. Segundo Campos (2015), a migração é considerada uma estratégia de sobrevivência diante das dificuldades decorrentes de fenômenos de causa natural (sem intervenção humana) ou humana, em busca do atendimento de necessidades que não são alcançadas nas regiões habitadas. Nesse contexto, de maneira geral, envolvem-se grupos sociais e não somente indivíduos isolados. Para o autor,

A maior parte dos indivíduos não migra só ou não tem a migração como um projeto exclusivamente pessoal e que, mesmo aqueles que migram de maneira forçada, muitas vezes provocam a migração de outros cujo estímulo migratório é determinado por relações de dependência, suporte ou afeto (CAMPOS, 2015, p. 273).

Além disso, Biagioni (2010) salienta que para compreender os processos migratórios é necessário analisar os fluxos populacionais considerando tanto as perspectivas do local de origem, como do destino, ou seja, além de refletir sobre os mecanismos que influenciaram a movimentação dos grupos, também se faz necessária a análise das consequências para o local destino. Assim, é relevante para a sociedade como um todo entender a interação entre desenvolvimento e desigualdade estabelecida pelo processo migratório, uma vez que as políticas de desenvolvimento e o comportamento econômico das regiões são diretamente impactados pelos fluxos migratórios.

A partir do início do século XXI, os fluxos migratórios mais acentuados são caracterizados por: movimentos pendulares (movimento de trabalhadores que residem em uma cidade e trabalham em outra), processos de re-emigração, refluxos, entre outros modos compostos por expulsão e atração de populações tanto no local de origem quanto nas regiões destino, como migração de retorno. Em um contexto geral, no período recente, observa-se no Brasil a existência de um processo de rotatividade migratória, pois não existem mais locais de saliente redução ou retenção migratória (BEANINGER, 2012).

No Rio Grande do Sul (RS), por ser um território especializado na produção agrícola, além do desenvolvimento social e econômico de zonas urbano-industriais, o estado tende a desenvolver-se mais que outros locais do país devido um efeito multiplicador endógeno de renda (fator que mede proporcionalmente quanto a renda varia) (OLIVEIRA; PEREIRA; BLOIS, 2010). Desta forma, há maior ampliação de oportunidades, tornando o espaço atrativo para migrantes de diversas regiões do Brasil. Em consequência, quando comparado a outras regiões da federação, o RS apresenta saldos positivos de migração desde a década de 1970, embora, conforme pode ser observado nos últimos censos demográficos, esses resultados têm apresentado gradativa redução (JARDIM; BARCELLOS, 2005). 
O Vale do Taquari (VT), localizado na região central do RS e distante em torno de $150 \mathrm{~km}$ de Porto Alegre, foi colonizado por imigrantes açorianos, alemães e italianos, a partir de meados do século XVIII. Esta região está entre as regiões gaúchas que apresentaram fluxos migratórios intensificados do campo, intra e inter-regional, resultando assim, em um processo de urbanização crescente até a década de 1970 (BARDEN; AHLERT, 2003). Já na década seguinte, a região apresentou um crescimento demográfico inferior ao $\mathrm{RS}$, decorrente de movimentos migratórios para outras regiões (BARDEN et al.,2012).

No entanto, recentemente, observa-se um comportamento inverso, de modo que alguns municípios da região têm apresentado um crescimento acima da média como consequência do recebimento de fluxos migratórios. Segundo RS (2015), entre 2000-2010, o crescimento demográfico na região foi superior à média estadual, revelando a existência de dinamismo econômico regional e uma capacidade de atração de migrantes provenientes de outras regiões. Contudo, cabe ressaltar que esse processo de urbanização foi heterogêneo entre os municípios, os quais apresentaram características demográficas e econômicas distintas, como consequência dos processos emancipatórios, da mudança de residência da zona rural para a urbana, do surgimento de novas áreas urbanas e da intensificação atividades relacionadas a indústria e serviço regiões (BARDEN et al., 2012).

No que se refere ao desempenho econômico dessa região, este é próximo ao desempenho observado na média do Estado ao longo das últimas décadas. Contudo, em alguns momentos o VT demonstrou uma situação intra-regional desigual, uma vez que, não há homogeneidade entre os fatores de produção e a capacidade produção e geração de riqueza. Além disso, o rumo seguido pela região por vezes acompanhou o desempenho do estado e em outros foi mais acelerado e em alguns não acompanhou essa tendência. Essas características podem ter interferido nos processos de atração e repulsão, bem como, ter influenciado o processo migratório para a região (BARDEN et al. 2012).

No caso do VT, a distribuição de emprego e as atividades produtivas na região tem reforçado de maneira distinta a formação da riqueza e a capacidade produtiva da região. Por consequência, a prática produtiva em alguns setores é desigual e concentrada em alguns municípios. A dinâmica populacional da região está associada a disponibilidade dos fatores de produção, juntamente com ligações equivalentes a rede modal, o que proporciona vínculos significativos entre o eixo do desenvolvimento do RS e o VT (BARDEN; SINDELAR; SILVA, 2016).

Diante dessa realidade, o objetivo deste estudo foi compreender os motivos que instigaram as famílias a migrarem para o Vale do Taquari nos últimos 10 anos e quais os fatores que influenciaram o processo migratório recente, bem como, os efeitos da decisão de permanecer ou não na região. 
O trabalho está estruturado em quatro partes, além desta introdução. Na próxima seção faz-se uma revisão de literatura sobre a migração e seus determinantes. Em sequência, apresentam-se os procedimentos metodológicos, que foram utilizados para o desenvolvimento da pesquisa, e os resultados da pesquisa. Por fim, são apresentadas as considerações finais.

\section{Migração e fatores determinantes}

O movimento de um grupo ou de um único indivíduo para outra localidade, implicando em mudança de residência permanente ou temporária é denominado migração. As migrações se constituem como correntes populacionais que revelam as dinâmicas de regiões e se relacionam aos processos de urbanização e redistribuição espacial da população (BEANINGER, 2012).

Sandroni (1999) afirma que o movimento de indivíduos de uma localidade para outra é, juntamente com a natalidade e mortalidade, base para essas dinâmicas populacionais. Contudo, "devido à complexidade do próprio movimento migratório, não existe uma definição do conceito de migração que descreva todos os processos que estão intrinsecamente ligados à ação de migrar" (SILVA, 2008, p. 05).

De acordo com Duhram (1984), a migração é considerada um fenômeno cultural, pois, quando não há alternativas de ascensão social na cidade de origem, o processo migratório é tido como única alternativa de melhoria de sobrevivência social.

Do ponto de vista sociológico, Germani (1970) evidencia que o movimento migratório é importante para que ocorra a transição da sociedade tradicional para a sociedade moderna. $\mathrm{O}$ autor compreende a migração como um processo social, em que a população precisa ser mobilizada socialmente para que seja atraída para outro local. É com a participação social que os indivíduos se colocam disponíveis para migrar de um local para outro. Ademais, esse processo social vai além dos instrumentos do mercado de trabalho e esse sistema de mobilização social é necessário para a modernização dos países, em especial em desenvolvimento (GERMANI, 1970).

A decisão de migrar pode estar associada a vantagens e desvantagens econômicas, sociais e laborais, tais como: inexistência de oportunidades de ascensão profissional, baixos salários, desemprego etc., considerados fatores expulsivos da região de origem; ou oportunidades de estudo e qualificação profissional, disponibilidade de empregos, salários elevados, entre outros, caracterizados como fatores atrativos da região de destino (CASTRO, 2012).

Por este motivo, a migração também tende a estar correlacionada ao aumento monetário de renda, pressupondo-se assim, que uma mudança de localidade somente ocorrerá se os salários reais dos trabalhares superarem 
os custos financeiros e psicológicos envolvidos nesse processo de mudança (FUJITA et al., 2002).

A migração também pode representar uma melhoria da qualidade de vida. Segundo Brito (2009, p. 06), "emigrar em direção às regiões urbanas é a opção mais adequada quando o objetivo é a melhoria do padrão de vida, mesmo quando se considera a enorme adversidade que essas regiões impõem aos imigrantes e as suas famílias". Por isso, geralmente, os fluxos migratórios atrelados ao deslocamento de correntes populacionais de uma área pouco urbanizada, são considerados como um fator de expulsão, enquanto o movimento para regiões de grande incremento populacional é considerado fator de atração (BARCELLOS,1995).

Outrossim, os migrantes buscam não somente melhores salários, mas sim, vão ao encontro de melhores oportunidades nas regiões mais dinâmicas (OLIVEIRA; PEREIRA; BLOIS, 2010), como é o caso de pessoas que nascem em regiões menos desenvolvidas em movimento a favor das regiões metropolitanas, as quais oferecem um maior potencial produtivo (CORREA; SILVEIRA; BRADT, 2015). Além disso, a migração pode ser condicionada ao processo econômico que reflete a dinâmica de determinantes sociais (acesso a saúde, educação, transporte).

Os movimentos migratórios geralmente são classificados como deslocamentos voluntários ou forçados, sendo que a maioria dos processos dificilmente se enquadra a esses limites (SILVA, 2008). A migração pode ser vista como voluntária quando o desejo individual é o motivador da ação de mudança. Por outro lado, o deslocamento forçado ocorre quando fatores externos ao indivíduo são os pontos determinantes para a migração (CAMPOS, 2015).

Para Campos (2015), o trabalho é a principal fonte de sobrevivência e reprodução social, por isso, o autor entende essa busca pela sobrevivência como uma ação "forçada", visto que por falta de oportunidades no local de origem, o indivíduo se vê obrigado a deslocar-se para outra região, em busca de emprego e melhores salários.

Os migrantes são considerados uma classe social em movimento positivo e fundamental para o desenvolvimento do capitalismo. Esse grupo social é motivado pela participação no mercado de trabalho em busca de acumulação capitalista, porém, o nível de instrução do indivíduo pode ser um obstáculo no que se refere a adaptação deste no mercado de trabalho nas cidades maiores (BRITO, 2009).

Além disso, as relações de poder (relação de autoridade) também influenciam na tomada de decisão para a migração, uma vez que nem sempre os indivíduos do grupo familiar participam igualmente desse processo e tem seus interesses levados em conta. Existem diferentes aspectos que influenciam a propensão de migrar e caracterizam uma seletividade de idade e sexo, 
ocorrendo uma diferenciação entre os que irão migrar de forma voluntária ou involuntária (CAMPOS, 2015).

Em consequência, as relações familiares ou de grupos sociais (de afeto, suporte e até dependência) podem tornar o processo migratório em ação não autônoma, devido a relação de poder envolvida no processo de tomada de decisão em migrar, pois, muitos migrantes não migram só. Assim a migração pode não ser de ordem totalmente pessoal, uma vez que influencia outros do seu meio familiar a envolver-se neste processo (CAMPOS, 2015).

A migração também pode ser vista como um drama existencial, pois geralmente membros da família tendem a seguir o projeto migratório de um dos integrantes, mesmo que de forma resistente, como no caso de filhos menores e esposa (LUSSI, 2009).

A principal diferença nos fatores determinantes da migração individual e da migração familiar é que, no caso familiar, a migração impõe a necessidade de os membros negociarem perdas e ganhos intrafamiliarmente. Assim, devido ao custo implícito ao processo de barganha, tem-se que o retorno da migração familiar tende a aumentar menos proporcionalmente que os respectivos custos, os quais são variados e dependem da avaliação de muitos outros fatores. Por isso, a literatura migratória é unânime em afirmar que a família é um obstáculo ao deslocamento (BATISTA; CACCIAMALI, 2012, p. 521).

Em função de muitos migrantes não migrarem só, o processo migratório torna-se um movimento não emancipado, que por muitas vezes se dá em função do projeto migratório de outro membro do grupo familiar, comumente vinculado a ações capitalistas na pretensão de atingir melhores garantias de vida (CAMPOS, 2015).

Entretanto, tanto a falta de sucesso quanto os conflitos externos (decorrentes do ambiente) retiram dos migrantes a capacidade de reação e autoproteção diante das adversidades, além de serem agravadas pelo fator saudade entre outras variantes do processo. Isso torna os migrantes vulneráveis pois, estes já passam por um sistema de desenraizamento cultural no que se refere a família, sexualidade, afetividade, religião, entre outros (LUSSI, 2009). Para Teixeira, Braga e Beaninger (2012), a circularidade do processo migratório não se trata somente de busca por melhores condições de vida, mas também, de uma permanente construção identitária e recomposição de suas relações familiares.

As relações capitalistas frente a busca por melhores salários, juntamente com a dinâmica de mercado indicam que migrar por melhores condições de vida é considerado um processo "normal" desta forma, esse movimento pode ser considerado um deslocamento voluntário. Em oposição a essa dinâmica, pode-se dizer que não há normalidade em processos migratórios oriundos de 
luta pela sobrevivência, uma vez que, esse transcurso é forçado pois torna-se condicionado por sistemas socioeconômicos (CAMPOS, 2015). Além disso, muitos migrantes não assimilam a real dinâmica do território destino, podendo ser criada uma expectativa firmada em uma ilusão de território inexistente que normalmente não corresponde à realidade local (CASTRO, 2008).

Segundo o Ministério da Integração Nacional (BRASIL, 2012), devido as desigualdades regionais, há uma indução de movimentos populacionais em direção a localidades mais dinâmicas. Esse fator piora o fenômeno da megametropolização (desenvolvimento de cidades e localidades até se tornarem metrópoles), agravando situações de violência, pobreza e favelização.

As cidades mais urbanizadas possuem um maior poder de atração de migrantes, muito embora, esses locais nem sempre conseguem absorver todo o fluxo de pessoas atraídas para essa região, o que provoca desequilíbrios econômicos e sociais nesta localidade (OLIVEIRA; PEREIRA; BLOIS, 2010).

$\mathrm{O}$ processo de industrialização é responsável por um significativo deslocamento da população rural para as cidades, e, como esse fenômeno não ocorre de forma homogênea, algumas regiões ficam esvaziadas e outras adensadas, e isso agrava o processo de desigualdade regional (BARCELLOS, 1995).

As migrações para as metrópoles são consideradas uma arriscada busca pela sobrevivência. O mercado de trabalho exige uma lista de pré-requisitos e tornou-se muito mais rígido, isso torna o processo muito difícil para o migrante pobre que sai da zona rural, muitas vezes sem um nível educacional conseguir qualquer possibilidade de ascensão social, mesmo este estando dentro dos limites da classe trabalhadora (BRITO, 2009).

Recentemente, com o aumento da tecnologia e a ampliação das telecomunicações, as informações se disseminam facilmente e assim, divulgando a realidade dos grandes centros urbanos: criminalidade, desemprego, dificuldade de acesso a serviços públicos básicos. Portanto, as externalidades positivas que atraiam pessoas, dão lugar as externalidades negativas comprometendo a esperança dos migrantes de transformar em realidade os desejos de uma vida melhor (BRITO, 2009).

Em síntese, os movimentos migratórios influenciam as dinâmicas demográficas e o desenvolvimento das regiões através da modificação do comportamento econômico atrelados ao processo de urbanização. Em geral, a migração ocorre de áreas menos dinâmicas para regiões com maior nível de povoamento, contudo, essas localidades nem sempre conseguem absorver todo o fluxo de pessoas atraídas para a região provocando desequilíbrios econômicos, sociais e agravando o fenômeno da megametropolização.

Além disso, a migração geralmente não ocorre individualmente o que torna o processo migratório uma ação não autônoma, pois geralmente o indivíduo não migra só, porém, esta pode ser vista como um drama existencial 
quando alguns membros da família tendem a seguir o processo migratório de outro, mesmo que de forma resistente.

\section{Procedimentos metodológicos}

O presente estudo classificou-se como exploratório e descritivo, pois descreveu as características e comparou os fatores responsáveis pela migração das famílias para o Vale do Taquari com estudos anteriores disponíveis na literatura, contribuindo para a maior compreensão do problema. Além disso, quanto à natureza da abordagem tratou-se de uma pesquisa qualitativa, visto que pretendeu-se descobrir os fatores que influenciaram as famílias a migrarem para o VT no período recente.

A escolha da região ocorreu a partir dos dados apresentados no último Censo demográfico (IBGE 2010), que demonstrou que o VT apresentou o terceiro maior saldo migratório absoluto do estado, destacando-se pela taxa de crescimento populacional média de 0,89\% a.a., acima da média de crescimento estadual 0,49\% a.a.. Além disso, vinte dos trinta e seis municípios da região apresentaram taxas positivas de crescimento variando entre $0,08 \%$ a.a. em Taquari e 2,70\% a.a. em Fazenda Vilanova. Esse crescimento deuse principalmente em municípios urbanizados sendo que em locais como Encantado, Tabaí e Fazenda Vilanova as taxas foram positivas mesmo em áreas rurais. Já Lajeado, foi o município que apresentou a maior perda populacional na região rural seguido de Imigrante e Nova Bréscia (RIO GRANDE DO SUL, 2015, pg. 11).

Para tanto, o presente estudo foi desenvolvido em duas etapas. Primeiramente buscou-se a análise de informações sobre migração fundamentada em dados secundários. Na segunda etapa analisou-se as informações a partir de fontes primárias, mediante pesquisa exploratória, por meio de entrevistas, via questionário semiestruturado, realizadas junto a uma amostra de nove famílias selecionadas por conveniência, nos municípios: Arroio do Meio, Encantado, Estrela, Fazenda Vilanova, Lajeado, Roca Sales, Santa Clara, Tabaí e Teutônia, conforme Figura 01. Segundo a Secretaria de Planejamento, Mobilidade e Desenvolvimento Regional do RS, esses municípios apresentaram taxa de crescimento populacional entre 1,01\% e 4,25\% a.a. no período de 2000-2010, muito superior ao observado no Estado em que a população cresceu 0,49\% no mesmo período (RIO GRANDE DO SUL, 2015). 
Figura 01: Mapa da taxa de crescimento anual (2000-2010)

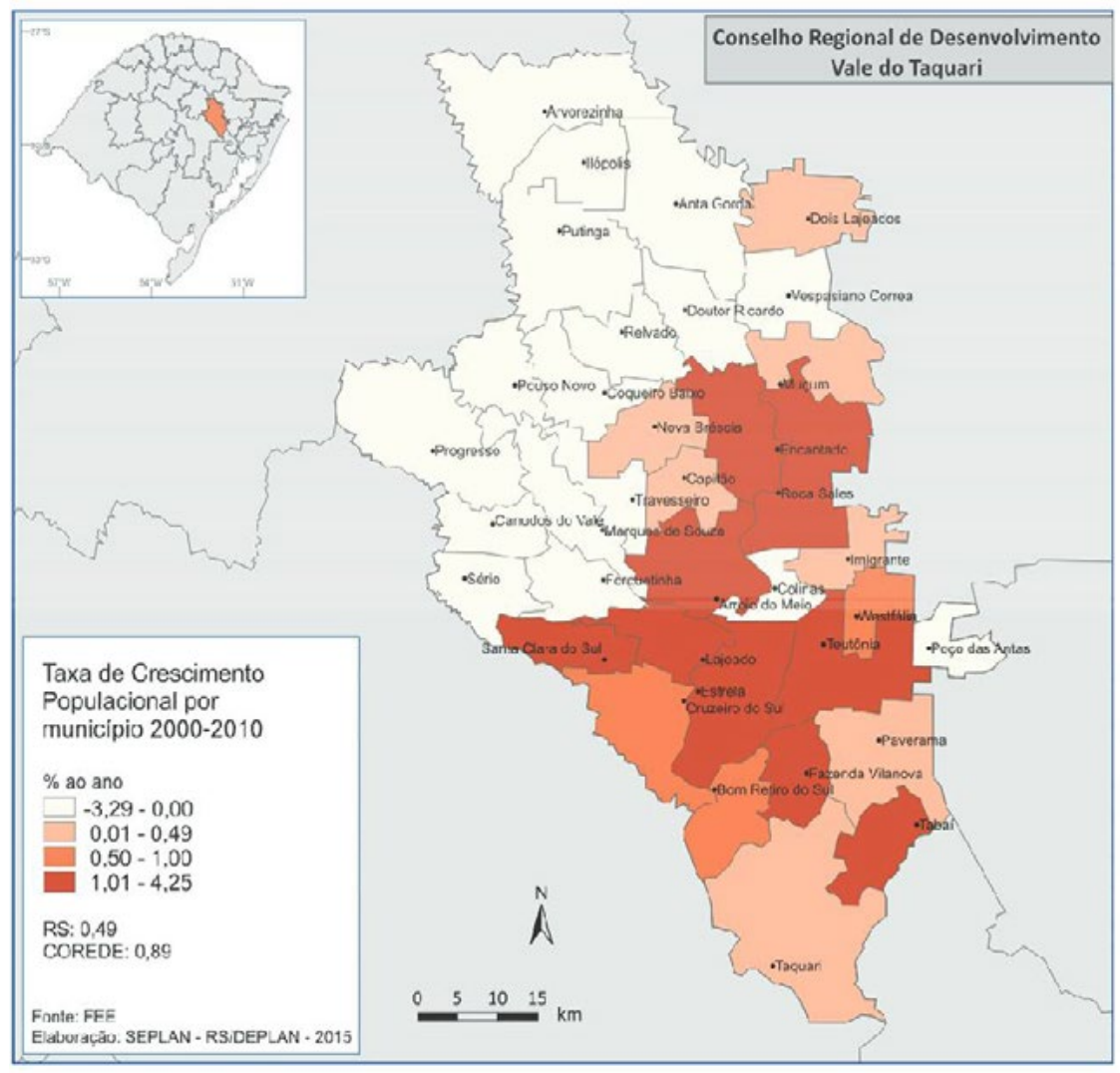

Fonte: SEPLAN (2015).

As entrevistas abordaram questões relativas as características socioeconômicas das famílias, além de um breve histórico de vida com as principais atividades exercidas na região de origem. Além disso, foram investigados os fatores que influenciaram a migração (motivações $x$ dificuldades) e perspectivas experimentadas neste processo. Buscou-se também pesquisar aspectos relacionados a qualidade de vida e as expectativas em relação ao futuro da família na região destino.

As entrevistas foram realizadas diretamente nas residências das famílias no primeiro semestre de 2017, sendo que, antes de iniciar as entrevistas os participantes assinaram o termo de consentimento livre e esclarecido, onde constou que os mesmos estavam cientes e declaram sobre a veracidade das informações fornecidas ao presente estudo. Cada um dos entrevistados foi identificado como: Entrevistado 1, 2, 3...9. Após a realização das entrevistas, cada uma delas foi degravada e foram analisadas com base na técnica de análise 
de conteúdo. A análise dos principais resultados da pesquisa é apresentada na próxima seção.

\section{Análise dos resultados}

O presente estudo teve o intuito de compreender quais as principais causas que levam as famílias a migrarem para o Vale do Taquari, compreender quais os fatores de atração para a região e quais as perspectivas das famílias em relação a localidade destino.

O perfil dos entrevistados revelou que a maioria dos entrevistados são casados (8), com idades em torno de 40 anos de idade e média de 1,6 filhos por família, cujas as idades variavam entre 1 a 28 anos e somente uma família não possuía filhos. Nas entrevistas, não foram fornecidas informações quanto a origem étnica, a religião e escolaridade, por pretensão dos entrevistados. Além disso, a maioria dos respondentes foram mulheres (8) devido a questão de tempo, acesso e contatos.

A renda familiar média dos entrevistados foi elevada (aproximadamente $\mathrm{R} \$ 7.700,00)$, em comparação ao rendimento domiciliar per capita no estado do RS (o qual segundo IBGE (2016) é de R $\$ 1.554,00$ ), sendo que para cinco famílias a renda é derivada de empreendimentos próprios (indústria e comércio), para duas famílias é originada de trabalhado assalariado e nas outras duas é decorrente de consultorias e bolsa de estudos. Em relação as habitações, cinco famílias residiam em moradias próprias e quatro em residências alugadas.

Nas regiões de origem, os entrevistados exerciam as mais variadas atividades associados aos setores de comércio e indústria, tais como: atendente de loja, responsável técnico de laboratório, estudante, moto-taxi, consultoria, professor e médico. Já no VT cinco entrevistados passaram a ser empresários, os demais trabalham com as mais variadas funções: trabalhador assalariado (1), pesquisador (1), consultor (1) e médico (1), atividades estas similares as praticadas na região de origem.

Quanto as regiões de origem das famílias entrevistadas, sete são provenientes das mais diversas regiões do Estado (Dois Irmãos, Porto Alegre, Rosário do Sul, Santa Rosa, Santiago, Três Cachoeiras e Três Passos) e duas de outras localidades do Brasil (São Paulo e Cuiabá), conforme Figura 02. Em consequência, podemos observar que as famílias migraram de regiões com características e realidades locais distintas.

Para as duas entrevistas oriundas de regiões de fronteira do RS (uma da fronteira Oeste e a outra da fronteira Sul), a realidade na região de origem era difícil, com poucas opções de emprego e lazer conforme expõe o entrevistado 1: "a gente é da fronteira, quem é rico é rico, e quem é pobre é pobre, né? Então lá predominam ricos fazendeiros. Então lá quem tem dinheiro tem, e quem não tem é bem complicado. Emprego é muito pouco". Essa característica também foi evidenciada por mais uma entrevistada, a qual mencionou que a região 
de origem era ruim, com instabilidades no emprego, violências e sem muitas condições de lazer. Desse modo, observa-se que para essas famílias a decisão de migração esteve associada a busca de melhores oportunidades e condições de vida, conforme o exposto por Campos (2015), o qual entende a migração como uma estratégia para a sobrevivência, visto também como investimento para a melhoria das condições de vida (OLIVEIRA, PEREIRA e BLOIS, 2010). Por outro lado, na opinião das demais entrevistadas provenientes de outras regiões do Estado e do País, as condições de vida nas regiões de origem eram boas, variando apenas os atributos referidos (três respondentes haviam mencionada ainda a existência de boas opções de lazer).

Figura 02: Mapa da movimentação das regiões de origem dos migrantes em direção ao Vale do Taquari

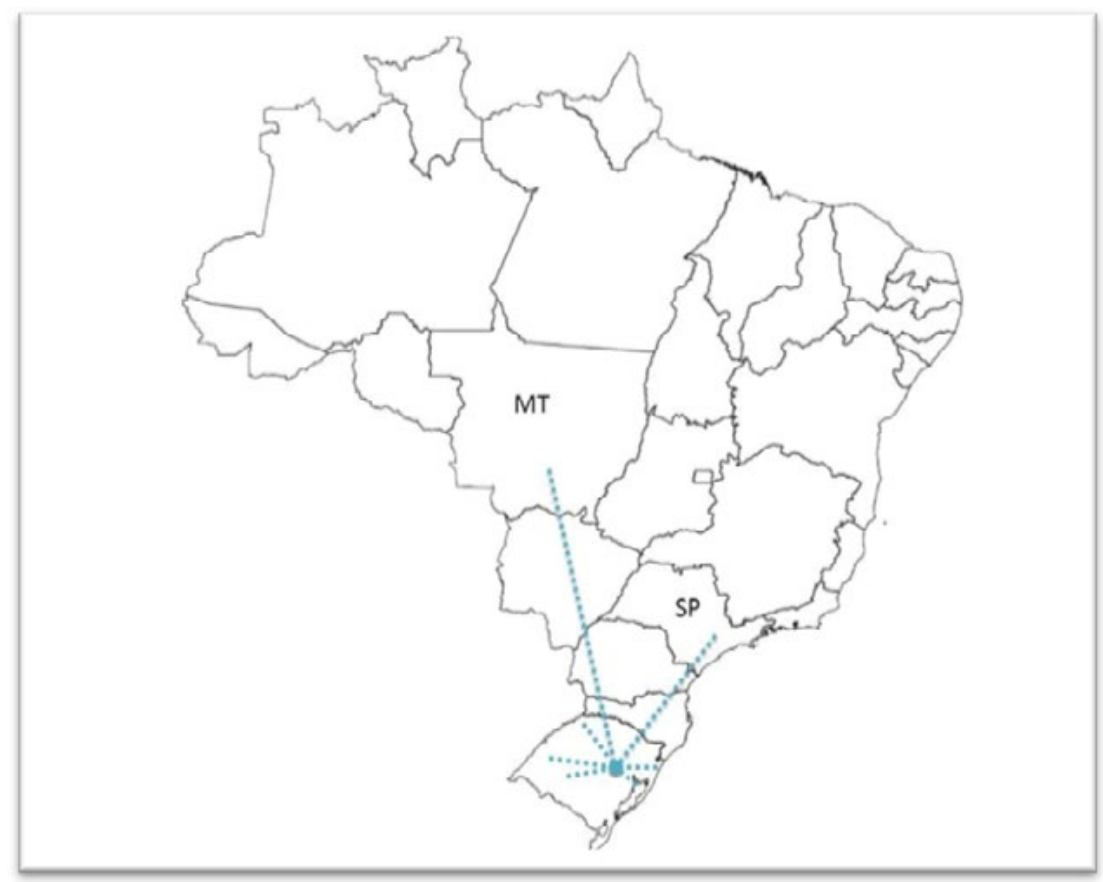

Fonte: Elaborado pelos autores.

Em consequência, quando questionados sobre os fatores motivadores para a saída das regiões de origem, as respostas foram similares, estando associadas basicamente ao mercado de trabalho. Dos entrevistados nesta amostra, cinco informaram que estavam em busca de melhores condições de trabalho e estudo, seguido por três que salientaram o desemprego como principal motivo para a migração, e uma respondente destacou a instabilidade no trabalho, juntamente com a violência e a insegurança no local de origem. Essas opiniões reforçam o destacado por Bandeira (2012), segundo o qual, em 
regiões com boas oportunidades de trabalho torna-se desnecessária a partida da população em busca de melhores condições de vida, e por Barcellos (1995), para quem os principais fatores de expulsão estão associados ao baixo nível de vida das populações e a falta de oportunidades nas regiões mais empobrecidas.

Em contrapartida, quando questionados sobre os fatores de estímulo para a escolha do VT como região destino destacam-se principalmente as melhores condições de trabalho e a possibilidade de aberturas de empreendimentos próprios. A região foi considerada como um local que concede boas oportunidade de emprego, estudo e qualidade de vida, seguidos de um posicionamento geográfico estratégico que facilita o acesso as mais diversas regiões do estado, conforme pode ser observado nas afirmativas a seguir: "Porque aqui é um lugar que tem mais desenvolvimento, né? Tanto na educação quanto financeiro, né? Pra cá é um lugar assim ó, é o oposto da onde nós morava" (Entrevistado 01); "Porque quando vai para Porto Alegre, todo mundo passa por Lajeado, né? Então, vieram conhecer a cidade, e viram que o era, que tinha um potencial, assim, de crescimento bem maior que Três Passos" (Entrevistado 3); "tem bastante universidades, faculdades envolta, possibilidades que a gente acha pra trabalhar" (Entrevistado 5).

Assim, confirma-se que a migração é influenciada por fatores atrativos na região destino e expulsivos na região de origem, com tendência ao deslocamento de migrantes de áreas pouco povoadas para localidades mais desenvolvidas (CASTRO, 2012). Somente a necessidade de melhorar as condições de vida é capaz de levar o indivíduo a abandonar sua terra natal, e essa ação não se dá somente em função da miséria, mas também, vai em busca de melhoria social (DUHRAM, 1894).

Em relação a quantidade de vezes em que realizaram uma mudança, seis dos entrevistados relataram ter saído da sua terra natal somente para residir na habitação atual no VT, enquanto quatro informaram já ter migrado mais vezes. Além disso, no que se refere ao tempo de residência no destino, este variava entre 9 meses a 10 anos.

Além disso, analisando a amostra entrevistada, observou-se que a saída da região de origem, a migração caracterizou-se como uma ação voluntária na maioria dos casos, com todos os membros da família de acordo com essa ação. Para Campos (2015), a migração é considerada voluntária quando os motivadores para essa ação são o desejo e a vontade individual. A família geralmente é um obstáculo para a ação da migração, pois esta impõe a necessidade de negociação de perdas e ganhos de todos os membros do grupo (BATISTA; CACCIAMALI, 2012), porém não foram mencionados empecilhos e ou obstáculos na amostra pesquisada.

Quando questionados sobre os principais contratempos relacionados ao processo de migração para a região destino, foram mencionados os obstáculos para encontrar moradia, a concorrência, a solidão, a rejeição e contrariedades nos primeiros contatos com a comunidade local, bem como dificuldades para 
adaptar-se as rotinas de uma cidade de interior. De outra parte, somente uma família afirmou que não houve nenhum tipo de dificuldade neste transcurso.

No que tange aos vínculos comunitários nas regiões de origem, seis respondentes declararam possuir algum tipo de elo na sociedade de origem. Em contrapartida, sobre sua inserção na nova comunidade, cinco entrevistados responderam que esta ocorreu sem maiores problemas, três relataram que a mesma muito rápida e apenas uma família declarou que foi ruim. Porém, a maioria delas (cinco) expôs que não mantiveram novas conexões sociais.

Os entrevistados ainda foram questionados sobre políticas públicas desenvolvidas nas regiões de origem e no Vale do Taquari. Em relação a saúde e assistência social, sete famílias avaliaram a saúde na localidade natal como boa e apenas duas como ruim. Quando em comparativo com o VT, quatro avaliaram os serviços oferecidos como bons; duas respondentes manifestaram que o atendimento é bom, porém poderia haver mais opções de profissionais e serviços prestados; duas classificaram como bons, porém enquanto para uma o acesso é rápido e fácil, outra destacou que existem menos opções de serviços e profissionais; e somente um dos respondentes classificou o serviço prestado como ruim. Por outro lado, cabe destacar ainda que para nenhuma das famílias entrevistadas a saúde e assistência social foram pontos motivadores para a migração ao VT.

No que se refere a educação nas regiões de origem, seis dos entrevistados a julgam como boa, para dois ela é ruim e um deles mencionou ser catastrófica, conforme explana o entrevistado 5: "Catastrófica! É a única palavra! É assim mesmo! A gente visitou bastante lugares até a gente chegou a achar um lugar que felizmente era perto da nossa residência. Municipal nem pensar. É muito horrível!". Sobre a instrução oferecida no VT, oito classificaram ela como sendo boa, dos quais quatro destacaram haver mais opções de estudo, e destes dois ainda acrescentaram a fácil acessibilidade, e somente um entrevistado considera o VT como um local onde o ensino particular oferecido é de baixo custo em comparação à capital do estado. Além disso, em dois casos analisados, o acesso ao ensino superior foi um ponto motivador para a escolha de local destino como comenta o entrevistado 4: "Foi, isso foi um motivador, foi muito. Então, com certeza foi um motivador a questão do ensino. Depois eu acabei conhecendo escolas de ensino fundamental e ensino médio que aqui são muito boas assim. Aqui, pra questão de depois filhos e uma coisa assim, mas eu daí não precisei, eu vim direto pra faculdade, né?".

Ademais, também se questionou sobre aspectos associados a segurança pública nas regiões de referência. Em relação a esse fator, os migrantes mencionam a segurança na origem como boa (três entrevistados), ou a classificaram como sendo melhor na terra natal por se tratar de uma localidade menor (três entrevistados). Por outro lado, um afirmou que esta era ruim, por ser uma cidade maior e um a avaliou como péssima. Já a segurança no VT foi qualificada em três dos casos como sendo uma região que possui boa segurança 
por ser localizada no interior, porém, para dois entrevistados ela foi considerada ruim por ser uma cidade maior. Também para dois dos entrevistados a região destino foi classificada como pior do que na região de origem enquanto que outros dois avaliaram como uma localidade onde a segurança é boa.

Nas entrevistas, ainda foi destacado por duas famílias que a segurança do VT foi tratada como um ponto motivador para a escolha deste local para moradia, conforme salienta o Entrevistado 6: "Quando a gente veio pra cá isso foi um dos pontos positivos também, da vida mais do interior, de poder sair caminhando na rua de noite, aquela coisa toda". Assim, confirma-se o exposto na literatura onde menciona-se que são os determinantes sociais que condicionam a migração em direção as oportunidades oferecidas pelas regiões mais desenvolvidas (CAMPOS, 2015; BARCELLOS, 1995).

No que concerne às perspectivas que os migrantes dispunham em relação a região de destino, todos os entrevistados afirmaram que estas foram supridas, sendo que 5 alegaram que as expectativas foram supridas além do pressentido, conforme Entrevistado 1: "Até mais do que a gente esperava. É mais porque tu, quando a gente chegou aqui, a gente teve que fazer o nosso lugar. Começar do zero"; para o Entrevistado 3: "Sim. Todas além das expectativas"; o que também foi confirmado pelo Entrevistado 4, que mencionou: "Nossa! Superou as expectativas. É, superou as expectativas mesmo. Nossa! Mais do que supridas! Acho que se alguém me dissesse assim há seis anos atrás que hoje eu estaria formada, teria feito faculdade e o [marido] teria negócio próprio eu não ia acreditar. Eu não ia acreditar". Assim, o migrante é um ser racional capaz de desenhar sua trajetória de forma a se adequar ao mercado de trabalho. Esta tende a ser amplamente favorável em relação aos benefícios de melhoria de vida, mesmo quando se trata das adversidades que a região destino impõe sobre a família (BRITO, 2009).

E por fim, ainda se questionou os migrantes em relação às expectativas quanto ao futuro. Neste sentido, apenas uma família mencionou o interesse em migrar novamente para outro local do Vale do Taquari que seja mais desenvolvido do que a cidade atual, enquanto que os demais (oito) acreditam que o futuro lhes reserva bons acontecimentos, crescimento constante com prosperidade e qualidade de vida nos municípios de residência atual.

\section{Considerações Finais}

No período recente o Vale do Taquari apresentou uma taxa de crescimento demográfico superior à média estadual, revelando a existência de dinamismo econômico regional, assim como, de capacidade de atração de migrantes provenientes de outras regiões. Neste sentido, este estudo contribuiu para compreender melhor esse processo.

Os principais motivos que instigaram as famílias migrantes a escolherem esta região estão atrelados a crença de uma localidade próspera, desenvolvida, 
com oportunidades de ascensão profissional e pessoal, boas oportunidades de emprego, educação e possibilidade de abertura de novos empreendimentos, sendo o trabalho e renda os principais fatores de atração para este lugar.

Além disso, quanto as principais causas para a migração das regiões de origem destacam-se a busca por melhores condições de vida. Neste sentido, o VT é tido como um local que dispõe aos seus moradores qualidade de vida, além de facilitar o acesso as mais diversas regiões do Estado. Como consequência, no que tange as perspectivas quanto ao futuro dos migrantes, a maioria acredita em um futuro próspero, com desenvolvimento pessoal e profissional. E, embora mencionados aspectos associados a saúde, assistência social e segurança, estes não foram decisivos nos processos migratórios.

Sintetizando, a investigação corrobora os pontos mencionados na revisão de literatura, pois os migrantes caracterizam-se por serem heterogêneos e estarem inseridos em um ambiente global em constantes transformações. Estes indivíduos migram em busca de melhores oportunidades, salários, educação e qualidade de vida (BEANINGER, 2012; CAMPOS, 2015; OLIVEIRA; PEREIRA; BLOIS, 2010).

\section{REFERÊNCIAS}

BARCELLOS, Tanya M. de. Migrações internas: os conceitos básicos frente à realidade da última década. Ensaios FEE, Porto Alegre, 1995. Disponível em: <http:/ / revistas. fee.tche.br/index.php/ensaios/article/view/1755/2123>. Acesso em: 03 out. 2016.

BARDEN, J. E. ; SINDELAR, F. C. W.; CONTO, S. M; AHLERT, L.; SANTOS, R. O fluxo migratório no Vale do Taquari/RS e as implicações sobre a dinâmica da economia. $8^{\circ}$ Encontro de Economia Gaúcha - FEE, Porto Alegre, 2016. Disponível em: <http://www.pucrs.br/negocios//wp-content/uploads/sites/6/2016/03/45_ FERNANDA-CRISTINA-WIEBUSCH-SINDELAR.pdf>. Acesso em: 31 mai. 2017

BARDEN, J. E. ; SINDELAR, F. C. W.; CONTO, S. M.; AHLERT, L.; SILVA, G. R. Análise da dinâmica da estrutura produtiva do COREDE Vale do Taquari no período de 1985 a 2014. $8^{\circ}$ Encontro de Economia Gaúcha 2016Caxias do Sul. Anais XI Encontro. Caxias do Sul: Editora UCS, 2012.

BARDEN, Júlia. E.; AHLERT, Lucildo. Fluxos migratórios e distribuição da renda interna na evolução da economia do vale do Taquari no período de 1930-70.

Estudos do CEPE (UNISC), v. 17, p. 61-89, 2003. Disponível em: <http:/ /www. cicvaledotaquari.com.br/portal/wpcontent/uploads/fluxos_migratorios_jornadas. pdf $>$ Acesso em: 29 ago. 2016.

BATISTA, Natália F., CACCIAMALI, Maria C., Migração familiar, trabalho infantil e ciclo intergeracional da pobreza no estado de São Paulo. Nova econ. vol.22 no.3, Belo Horizonte Set/Dez. 2012. Disponível em: <http:/ /www.scielo.br/pdf/neco/v22n3/ a04v22n3.pdf>. Acesso em: 29 ago. 2016 
BEANINGER, Rosane. Rotatividade migratória: um novo olhar para as migrações internas no brasil. REMHU, Rev. Interdiscip. Mobil. Hum, 2012 Disponível em: <http:/ / www.scielo.br/pdf/remhu/v20n39/v20n39a05.pdf>. Acesso em: 29 ago. 2016.

BEANINGER, Rosane. Migrações internas no Brasil no século 21: entre o local e o global. ABEP Associação Brasileira de Estudos Populacionais, 2012. Disponível em: < http:/ /www.abep.nepo.unicamp.br/xviii/anais/files/ST24[611]ABEP2012.pdf>. Acesso em: 06nov. 2016

BIAGIONI, D. Mobilidade Social e Migração Interna no Brasil. Instituto Universitário de Pesquisas do Estado do Rio de Janeiro. Centro de Estudos das Metrópoles (CEM/ CEBRAP), 2010. Disponível em: <http:/ / docplayer.com.br/4913169-Mobilidadesocial-e-migracao-interna-no-brasil-1.html>. Acesso em: 02 out. 2016.

BRITO, Fausto. As migrações internas no brasil: um ensaio sobre os desafios teóricos recentes. UFMG/Cedeplar, Belo Horizonte, set. 2009. Disponível em: <http:/ /www. cedeplar.ufmg.br/pesquisas/td/TD\%20366.pdf>.Acesso em: 28 set. 2016.

CAMPOS, Marden Barbosa de. Características demográficas e a voluntariedade da migração. REMHU, Rev. Interdiscip. Mobil. Hum. vol.23 no.45 Brasília jul./dez. 2015. Disponível em: <http:/ / www.csem.org.br/remhu/index.php/remhu/article/ view/448>. Acesso em: 04 out. 2016.

CASTRO, Fátima Velez de. A europa do outro - a imigração em portugal no início do século XXI. Estudo do caso dos imigrantes da Europa de Leste no concelho de Vila Viçosa. ACIDI, São Paulo,Dez. 2008. Disponível em:<http:/ / www.om.acm.gov. pt/documents/58428/179891/tese_16.pdf/e3c5d445-220f-4e10-a39d-af15357be31f >. Acesso em: 03 out. 2016.

CASTRO, Fátima Velez de. Imigração e territórios em mudança. Teoria e prática (s) do modelo de atração-repulsão numa região de baixas densidades. Cadernos de Geografia. Coinbra, 2012. Disponível em: <http:/ /www.uc.pt/fluc/depgeo/ Cadernos_Geografia/Numeros_publicados/CadGeo30_31/Eixo2_5>. Acesso em: 10 out. 2016.

CORREA, José C. S., SILVEIRA, Rogério L. L. de, BRANDT, Grazielle B.O Corede Alto Jacuí no contexto da PNDR/CNDR: Reflexões sobre a questão migratória. Redes Revista do desenvolvimento regional. Set/Dez 2015. Disponível em: <https:/ / online. unisc.br/seer/index.php/redes/issue/view/303>. Acesso em: 27 out. 2016.

CUNHA, José M. P. da. Migração e urbanização no Brasil: alguns desafios metodológicos para análise. São Paulo Perspec. vol.19 no.4, São Paulo Out. Dez. 2005. Disponível em: <http://www.scielo.br/scielo.php?script=sci_ arttext\&pid=S0102-88392005000400001>. Acesso em: 04 out. 2016.

DURHAM, Eunice. A caminho da cidade - A vida rural e a migração para São Paulo. São Paulo. Perspectiva, 1984. 
ESTADO DO RIO GRANDE DO SUL (RS). Secretaria de planejamento, mobilidade e desenvolvimento regional, Perfis Socioeconômicos, Perfil socioeconômico 2015 Vale do Taquari. Disponível em: <http:/ / planejamento.rs.gov.br/upload/ arquivos /201603/17095341-perfis-regionais-2015-vale-do-taquari.pdf > . Acesso em: 27 out. 2016.

\section{FUJITA, M.; KRUGMAN, P. R.; VENABLES, A. J.; CARDOSO, S. A. P. Economia} espacial. São Paulo: Futura, 2002.

GERMANI, GINO, Sociologia de lamodernization, Buenos Aires, 1970.

INSTITUTO BRASILEIRO DE GEOGRAFIA E ESTATÍSTICA - IBGE. Renda domiciliar per capita 2016. Disponível em: <ftp:/ / ftp.ibge.gov.br/Trabalho_e_ Rendimento/Pesquisa_Nacional_por_Amostra_de_Domicilios_continua/Renda_ domiciliar_per_capita/Renda_domiciliar_per_capita_2016.pdf>. Acesso em: 26 fev. 2018.

JARDIM, M. L, BARCELLOS, T.M. Os movimentos populacionais no Rio Grande do Sul: uma visão inter e intraCoredes. Revista Ensaios FEE, n.26, Porto Alegre, 2005. Disponível em: <http://revistas.fee.tche.br/index.php/ensaios/article/view/2079>. Acesso em: 02 out. 2016.

KLEIN, Amarolinda Zanella, et. al. Metodologia de pesquisa em administração: Uma abordagem prática. Editora Atlas, SP. 2015.E-book. Disponível em: <https:/ / integrada.minhabiblioteca.com.br/\#/books/9788522495313/cfi/3!/4/4@0.00:66.4> Acesso em: 24 out 2016.

LUSSI, C. Conflitos e vulnerabilidades no processo migratório. Centro Scalabriniano de Estudos Migratórios, 2009. Disponível em: <http:/ / www.csem.org.br/2009/ conflitos_e_vulnerabilidades_no_processo_migratorio.pdf $>$. Acesso em: 03 out. 2016.

OLIVEIRA, Guilherme de, PEREIRA, André da Silva, BLOIS, Henrique Dias, Especialização agropecuária e os fluxos migratórios no estado do rio grande do sul 1970-2000. Ensaios FEE. Disponível em: <cdn.fee.tche.br/eeg/5/47.doc>. Acesso em: 08 ago. 2016.

SAMPIERI, Roberto H., COLLADO, Carlos F., LUCIO, María. P. B. Metodologia de pesquisa. 5. ed. Porto Alegre: AMGH, 2013.

SANDRONI, Paulo. Novíssimo dicionário de economia. Best Seller, São Paulo. 1999. Disponível em: <https:/ / pt.scribd.com/doc/6965717/Paulo-Sandroni-NOVISSIMODICIONACIRIO-DE-ECONOMIA>. Acesso em: 06 nov. 2016.

SILVA, Patrícia Oliveira da. Aspectos gerais da migração fronteiriça entre Brasil e Bolívia. ABEP. São Paulo, 2008. Disponível em: <http:/ / www.abep.nepo.unicamp.br/ encontro2008/docspdf/ABEP2008_1491.pdf>. Acesso em: 06 nov. 2016. 